\title{
Involvement of endothelium-dependent and -independent mechanisms in midazolam-induced vasodilation
}

\author{
Gian Luca Colussi, Alessandro Di Fabio, Cristiana Catena, Alessandra Chiuch and Leonardo A Sechi
}

Benzodiazepine (BDZ) infusion has been shown to reduce blood pressure in both humans and animals. Although the inhibitory effects of BDZ on the central nervous system have been well documented, less is known about the direct effects of BDZ on the vascular bed. The aims of this study were to assess the effects of the BDZ midazolam on the vascular system in C57/BL6 mouse aortic rings and to investigate the mechanisms of its direct vascular action. We found that midazolam induced reversible, dose-dependent vasodilation in potassium- and phenylephrine-precontracted rings. In rings that were precontracted with potassium or phenylephrine, treatment with $10 \mu \mathrm{mol} \mathrm{I}^{-1}$ midazolam increased vasodilation by 15 and $60 \%$, respectively, compared with baseline. Vasodilation increased by 80 and $87 \%$, respectively, after treatment with $50 \mu$ mol I ${ }^{-1}$ midazolam. Only the low concentration of midazolam $\left(10 \mu \mathrm{mol} \mathrm{I}^{-1}\right)$ induced endothelium-dependent vasodilation in phenylephrine-precontracted rings. Vasodilation increased by $60 \%$ in rings with endothelium and by $20 \%$ in rings without endothelium. Conversely, only the high concentration of midazolam $\left(50 \mu \mathrm{mol} \mathrm{I}^{-1}\right)$ reduced the $\mathrm{CaCl}_{2}$-induced vasoconstriction of aortic rings with $\mathrm{EC}_{50}$ (the concentration giving $50 \%$ of the maximal effect) values of 1 and $6 \mathrm{mmol} \mathrm{I}^{-1}$ for vehicle- and midazolam-treated rings, respectively. Furthermore, the incubation of phenylephrine-precontracted rings with an inhibitor of the nitric oxide synthase (NOS) NG-nitro-L-arginine methyl ester or the inhibitors of central or peripheral type BDZ receptors (flumazenil or PK 11195, respectively) produced no change in midazolam-induced vasodilation. Thus, low concentrations of midazolam induce vasodilation via an endothelium-dependent mechanism that does not involve NO production. In contrast, high concentrations of midazolam induce vasodilation via an endothelium-independent mechanism that implies reduced sensitivity of aortic rings to calcium ions. Additionally, neither the central $\gamma$-amino-butyric acid receptor type A nor the peripheral type BDZ receptors seem to be involved in the mechanism of midazolam-induced vasodilation.

Hypertension Research (2011) 34, 929-934; doi:10.1038/hr.2011.62; published online 26 May 2011

Keywords: calcium-channel blockers; endothelium; GABA-A receptor; midazolam; vasodilation

\section{INTRODUCTION}

Peripheral vascular resistance has a fundamental role in controlling blood pressure. Peripheral vascular resistance depends directly on vascular tone that results from the balance between vasoconstrictor and vasodilator factors acting on vascular smooth muscle cells. Vasoconstriction depends on excitatory stimuli that increase intracytoplasmic calcium entry. Specifically, calcium increases in the cytoplasm of vascular smooth muscle cells by passing through voltage- and receptor-operated calcium channels located in the plasma membrane and in the sarcoplasmic reticulum, respectively. This cytoplasmic calcium binds calmodulin and activates myosin light-chain kinase, which phosphorylates the regulatory myosin light chain and leads to vascular smooth muscle contraction. ${ }^{1}$ Drugs that inhibit voltageoperated calcium channels are very effective in reducing vascular tone, peripheral vascular resistance and, therefore, blood pressure. ${ }^{2}$
Unlike vasoconstriction, vasodilation depends on the endothelium. Stimulation of endothelial factors such as nitric oxide (NO) reduces intracellular calcium content, leading to relaxation of vascular smooth muscle and, therefore, vasodilation. Drugs that increase NO availability are highly effective for reducing blood pressure. ${ }^{3}$ The benzodiazepines (BDZs) represent an old class of drugs that has been shown to have direct vascular vasodilatory effects on both arteries and veins. ${ }^{4}$ BDZs can reduce blood pressure in experimental ${ }^{5}$ and clinical settings. ${ }^{6}$ In addition, BDZs can reduce blood pressure both indirectly, by central inhibition of the autonomic neurocardiac system and the control of the baroreflex, ${ }^{7,8}$ and directly, by dilating the blood vessels in the vascular beds of animal models. ${ }^{4,9-11}$ Nonetheless, the mechanism by which BDZs stimulate vasodilation remains unclear.

As BDZs are classically involved in the regulation of chloride ion channels, the mechanism of BDZ-induced vascular effects might be 
mediated by the regulation of ion channels in blood vessels. In support of this possibility, BDZs at high concentrations inhibit vascular calcium channels, which are sensitive to membrane voltage changes. ${ }^{12,13}$

At low (nanomolar) concentrations, BDZs bind to a non-neurological receptor in peripheral tissues. This non-neurological receptor is identified as 'peripheral type benzodiazepine receptor' or, according to the most recent nomenclature, ' $18-\mathrm{kDa}$ Translocator Protein' (TSPO). ${ }^{14}$ The cardiovascular system, including the aorta, presents high levels of TSPO. ${ }^{15}$ Although specific stimulation of TSPO can induce vasodilation in some models, possibly by inhibiting voltageoperated calcium channels, ${ }^{16,17}$ its involvement in BDZ-induced vasodilation appears to be controversial. ${ }^{18,19}$

The aim of this study was to assess the vascular effects of BDZs and the possible mechanisms involved in their direct vascular action. We hypothesized that such mechanisms might involve endothelial-dependent and -independent pathways. For this purpose, we used aortic rings of C57/BL6 mice, and we chose the BDZ midazolam because of its demonstrated vascular effects. ${ }^{6,20}$

\section{METHODS}

\section{Mice}

For this study, 2-month-old male C57/BL6 mice (Harlan Italy-San Pietro al Natisone, Udine, Italy) were used. Mice were kept in standard cages under a 12-h light/dark cycle, fed a standard diet and cared for according to the guidelines of our institution. The experiments were performed after the mice had been acclimatized to their housing conditions for at least 1 week. On the day of the experiments, mice were weighed and then decapitated. The thoracic aorta was dissected from each mouse, cleaned of adhering perivascular tissue and placed in a cold Krebs-Henseleit bicarbonate buffer solution with the following composition (in mmoll ${ }^{-1}$ ): $\mathrm{NaCl} 118.3, \mathrm{KCl} 4.7, \mathrm{CaCl}_{2} 2.5, \mathrm{MgSO}_{4} 7 \mathrm{H}_{2} \mathrm{O}$ 1.2, $\mathrm{KH}_{2} \mathrm{PO}_{4}$ 1.2, NaHCO 325.0 and glucose 5.6. Experiments conformed to institutional and national guidelines and were approved by the Italian Ministry of Health.

\section{Evaluation of vascular reactivity}

Evaluation of vascular reactivity was performed as previously described. ${ }^{21}$ Aortic rings were suspended in isolated tissue baths filled with $20 \mathrm{ml}$ of Krebs solution continuously bubbled with a mixture of $5 \% \mathrm{CO}_{2}$ and $95 \% \mathrm{O}_{2}(\mathrm{pH}$ 7.37-7.42) at $37^{\circ} \mathrm{C}$. One end of the aortic ring was connected to a tissue holder and the other to an isometric force transducer. The analogical signal was acquired in a digital system (Biopac MP150-Biopac System, Traiskirchen, Austria) and analyzed by dedicated software (AcqKnowledge 3.0-Biopac System). Aortic rings were equilibrated for $90 \mathrm{~min}$ in unstretched conditions, and the Krebs solution was replaced every $20 \mathrm{~min}$. The length of aortic rings was increased stepwise during the equilibration period to adjust passive wall tension to $1.0 \mathrm{~g}$. Once basal tension was established, the length of the rings was not altered thereafter. Vasodilation of the aortic rings was expressed as the proportional difference between the contraction reached after treatment and the maximal contraction (baseline) reached with potassium chloride $\left(80 \mathrm{mmoll}^{-1}\right.$, Sigma, Milan, Italy) or phenylephrine $\left(1 \mu \mathrm{moll}{ }^{-1}\right.$, Sigma). Endothelial and smooth muscle function were tested by increasing concentrations of acetylcholine (dose-response curve from $10^{-9}$ to $10^{-5} \mathrm{moll}^{-1}$, Sigma) and nitroglycerin (dose-response curve from $10^{-9}$ to $10^{-6} \mathrm{moll}^{-1}$ ), respectively.

\section{Evaluation of endothelium involvement in midazolam-induced vasodilation}

Involvement of endothelium was assessed as previously described. ${ }^{21}$ We evaluated the concentration-dependent vascular effect of midazolam (doseresponse curve from $10^{-9}$ to $\left.5 \times 10^{-5} \mathrm{moll}^{-1}\right)$ on $\mathrm{KCl}-\left(80 \mathrm{mmoll}^{-1}\right)$ and phenylephrine-precontracted $\left(1 \mu \mathrm{moll}^{-1}\right)$ rings with or without endothelium. Endothelium was removed by gently rubbing the ring's lumen with a 28 -gauge needle tip. Then, rings were treated with acetylcholine $\left(1 \mu \mathrm{moll}^{-1}\right.$, Sigma $)$ and nitroglycerine $\left(1 \mu \mathrm{moll}^{-1}\right)$ to confirm the removal of the endothelium and assess each ring's integrity, respectively. The dependency of midazolam-induced vasodilation on endothelial $\mathrm{NO}$ production was evaluated after incubation of the rings with the non-selective NO synthase (NOS) inhibitor NG-nitro-larginine methyl ester $\left(300 \mu \mathrm{moll}{ }^{-1}\right.$, Sigma) for $40 \mathrm{~min}$. Effective NOS inhibition was assessed by verifying the lack of significant vasodilation induced by $1 \mu \mathrm{moll}^{-1}$ acetylcholine on phenylephrine-precontracted rings.

\section{Evaluation of the involvement of different BDZ receptor types in midazolam-induced vasodilation}

To assess the involvement of the central-type $\mathrm{BDZ}$ receptor, also known as the $\gamma$-amino-butyric acid receptor type A $\left(\mathrm{GABA}_{\mathrm{A}}\right)$, we used the method of Anwar and Mason on the rabbit basilar artery with some modifications. ${ }^{22}$ Aortic rings precontracted with $\mathrm{KCl}$ were treated either with increasing doses of GABA (dose-response curve from $10^{-9}$ to $10^{-4} \mathrm{moll}^{-1}$, Sigma) or, after incubation with the central-type BDZ receptor antagonist flumazenil $\left(1 \mu \mathrm{moll}^{-1}\right.$ for $10 \mathrm{~min}$ ), with midazolam (10 or $\left.50 \mu \mathrm{moll}^{-1}\right)$. We evaluated whether midazolam and GABA have a synergistic effect on vasodilation of the aortic rings by incubating KCl-precontracted rings with GABA $\left(100 \mu \mathrm{moll}^{-1}\right.$ for $\left.10 \mathrm{~min}\right)$ before midazolam treatment.

The involvement of the peripheral-type $\mathrm{BDZ}$ receptor/TSPO on midazolaminduced vasodilation was assessed as previously described. ${ }^{15}$ Phenylephrineprecontracted aortic rings were stimulated with specific TSPO ligands. Direct TSPO-mediated vasodilation was assessed by treating precontracted rings with increasing doses of the TSPO ligand Ro5-4864, a $4^{\mathrm{I}}$-chloro derivative of diazepam (dose-response curve from $10^{-9}$ to $10^{-4} \mathrm{moll}^{-1}$; Sigma). To evaluate possible synergistic effects between the TSPO agonist and midazolam, precontracted rings were incubated for $10 \mathrm{~min}$ with $10 \mu \mathrm{moll}^{-1}$ Ro5-4864 before stimulation with $10 \mu \mathrm{moll}^{-1}$ midazolam. The role of TSPO in midazolam-induced vasodilation was assessed by incubating precontracted rings with the specific TSPO ligand PK 11195, an isoquinoline carboxamide derivate $\left(1 \mu \mathrm{moll} l^{-1}\right.$; Sigma), for $10 \mathrm{~min}$ before stimulation with $10 \mu \mathrm{moll}^{-1}$ midazolam.

\section{Evaluation of the calcium antagonist property of midazolam}

To assess the calcium antagonist property of midazolam, we followed the method described by Hof and Vuorela. ${ }^{23}$ Briefly, the rings were first equilibrated and adjusted to a basal tension level of $1 \mathrm{~g}$ in a Tris buffer of the following composition (in mmoll ${ }^{-1}$ ): $\mathrm{NaCl} 134.8, \mathrm{KCl} 4.7, \mathrm{MgSO}_{4} .7 \mathrm{H}_{2} \mathrm{O} 1.2$ and $\mathrm{CaCl}_{2} \cdot 2 \mathrm{H}_{2} \mathrm{O} 2.5$, bubbled continuously with $100 \%$ oxygen. Second, the maximal vasoconstriction of the rings was assessed in normal calcium Tris buffer by treatment with $60 \mathrm{mmoll}^{-1} \mathrm{KCl}$. Third, the bath was exchanged with a calcium-free Tris bath solution containing $60 \mathrm{mmoll}^{-1}$ of $\mathrm{KCl}$, and increasing doses of calcium chloride were added as a vasoconstrictor $\left(10^{-5}\right.$ to $\left.10^{-1} \mathrm{moll}^{-1}\right)$. Vasoconstriction was measured in 10 and $50 \mu \mathrm{moll}^{-1}$ midazolam-pretreated rings and compared with vehicle. Vasoconstriction is expressed with reference to the maximal vasoconstriction reached by the same ring contracted with $60 \mathrm{mmoll}^{-1} \mathrm{KCl}$ under normal calcium conditions. The calcium-channel antagonist verapamil $\left(1 \mu \mathrm{moll}^{-1}\right)$ was used as a positive control.

\section{Statistical analysis}

All experiments were performed on four ring preparations obtained from the aorta of each of at least three mice. The data presented in Figures $1 \mathrm{a}$ and $\mathrm{b}$ and 5 were analyzed with one-way analysis of variance, and the data in Figures 3 and 4 were analyzed with two-way analysis of variance. Pairwise comparisons in Figures 1a and b, 3, 4, and 5 were performed with Bonferroni's method after analysis of variance. The data in Table 1 and Figure 2 were analyzed by paired Student's $t$-test. The dose-response curves in Figure 3 were fitted with a threeparameter equation, and $\mathrm{EC}_{50}$ (the concentration giving $50 \%$ of the maximal effect) values were calculated by non-linear regression analysis. Data are presented as the means and standard error. Differences were considered statistically significant at $P \leqslant 0.05$. Statistical analysis and graphs were prepared using GraphPad Prism version 5.01 for Windows (GraphPad Software, San Diego, CA, USA). 


\section{RESULTS}

The BDZ midazolam induced a reversible vasodilatory effect. The extent of this effect varied according to the concentration used and the type of precontraction stimulus. Specifically, mouse aortic rings treated with $10 \mu \mathrm{moll}^{-1}$ midazolam were dilated to 15 and $60 \%$ of their basal level after precontraction with potassium and phenylephrine, respectively (Figures 1a and b). Aortic rings treated with $50 \mu \mathrm{moll}^{-1}$ midazolam were dilated to 80 and $87 \%$ of baseline after precontraction with potassium and phenylephrine, respectively. Lower concentrations of midazolam had no vasodilatory effect on aortic rings precontracted with either stimulus. The midazolam-induced vasodilatory effect was reversible because the vasoconstrictive ability of the aortic rings under phenylephrine stimulus was restored after midazolam removal from the aortic rings' bath (Figure 2).

Midazolam-induced vasodilation was dependent on the presence of endothelium only at the lower concentration of midazolam. Specifically, aortic rings treated with $10 \mu \mathrm{moll}^{-1}$ midazolam were dilated to 60 and $20 \%$ of their basal level with and without endothelium, respectively. Aortic rings treated with $50 \mu_{\mathrm{moll}}^{-1}$ midazolam were dilated to the same extent (about 85\%) in rings with and without endothelium (Figure 3a).

The endothelium-mediated vasodilatory effect at the lower concentration of midazolam was not related to endothelial NO production. Aortic rings incubated with the NOS inhibitor NG-nitro-L-arginine methyl ester were dilated to the same percentage of the baseline following treatment with midazolam at either 10 or $50 \mu \mathrm{moll}^{-1}$ (Figure 3b).

The maximal vasodilatory effect at the high concentration of midazolam was calcium dependent. The $\mathrm{EC}_{50}$ value derived from the dose-response curve of aortic rings contracted with increasing doses of calcium chloride in a hyperpolarizing bath showed a significant rightward shift (Figure 4). This rightward shift away from aortic rings treated with vehicle $\left(E_{50} 1 \mathrm{mmoll}^{-1}\right)$ was present only in aortic rings treated with $50 \mu \mathrm{moll}^{-1}$ midazolam $\left(\mathrm{EC}_{50}\right.$ $\left.6 \mathrm{mmoll}^{-1}\right)$. In contrast, the dose-response curve of aortic rings treated with $10 \mu \mathrm{moll}^{-1}$ midazolam did not differ from that of the aortic rings treated with vehicle.

It has been previously shown that $\mathrm{BDZ}$-induced vasodilation can be mediated by the central type $\mathrm{GABA}_{\mathrm{A}}$ receptor. ${ }^{22,24,25}$ Therefore, we tested the effect of GABA and the $\mathrm{GABA}_{\mathrm{A}}$ receptor inhibitor flumazenil on aortic rings. Increasing doses of GABA did not induce vasodilation (data not shown). Furthermore, preincubation of aortic rings with GABA did not magnify the vasodilation induced by 10 or $50 \mu \mathrm{moll}^{-1}$ midazolam (Table 1). Accordingly, preincubation of aortic ring with $10 \mu \mathrm{moll}^{-1}$ flumazenil did not inhibit midazolam-induced vasodilation either at the low or at the high midazolam concentration (Table 1).

Furthermore, we found that TSPO did not participate in midazolam-induced vasodilation of aortic rings. Treatment of phenylephrineprecontracted rings with increasing doses of the TSPO ligand Ro54864 (dose-response curve from $10^{-9}$ to $10^{-5} \mathrm{moll}^{-1}$ ) did not induce vasodilation (data not shown). Accordingly, incubation of phenylephrine-precontracted rings with the TSPO ligand PK 11195 did not reduce midazolam-induced vasodilation (Figure 5). Only incubation with the high concentration $\left(10^{-4} \mathrm{moll}^{-1}\right)$ of Ro5-4864 reduced midazolam-induced vasodilation (up to $34 \%$ of the vehicle control) (Figure 5).

\section{DISCUSSION}

This study demonstrates that the BDZ midazolam induces vasodilation of the mouse aorta by two different concentration-dependent
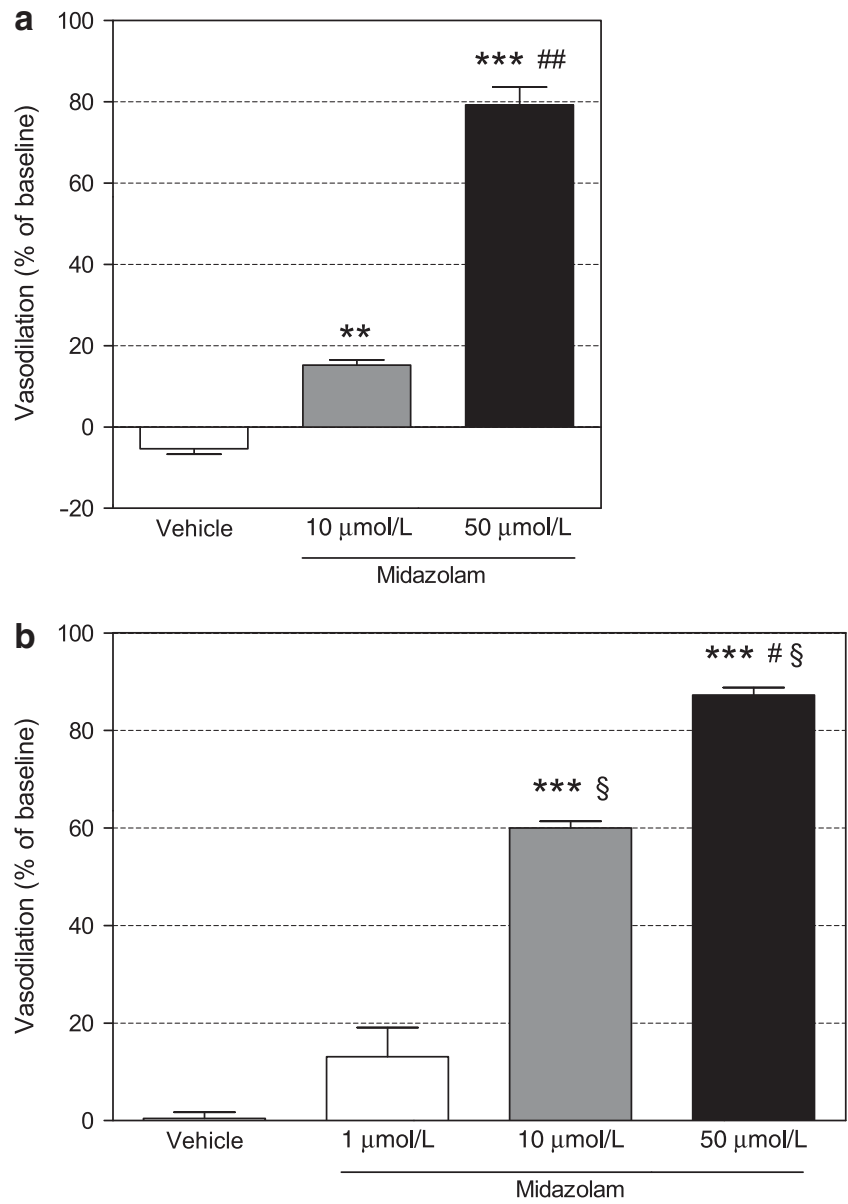

Figure 1 The dose-dependent vasodilatory effect of midazolam on mouse aortic rings. (a) Rings were precontracted with $80 \mathrm{mmol} \mathrm{I}^{-1} \mathrm{KCl}$. (b) Rings were precontracted with $1 \mu \mathrm{mol} \mathrm{I}^{-1}$ phenylephrine. Values are means \pm s.e.m. for 12 samples of aortic rings obtained from three mice. ${ }^{* *} P<0.01$, ${ }^{* * *} P<0.001$ vs. vehicle; ${ }^{\#} P<0.01$, ${ }^{\#} P<0.001$ vs. $10 \mu \mathrm{mol} \mathrm{I}^{-1}$ midazolam; $\$ P<0.001$ vs. $1 \mu \mathrm{moll}^{-1}$ midazolam by one-way analysis of variance and post-test pairwise comparisons by Bonferroni's method.

Table 1 Effects of the low and high concentrations of midazolam on $\mathrm{KCl}$ - or phenylephrine-precontracted aortic rings after incubation with GABA (experiment 1) or Flumazenil (experiment 2), respectively

\begin{tabular}{lcc} 
Incubation substance & Midazolam $\left(10 \mu \mathrm{mol}^{-1}\right)$ & Midazolam $\left(50 \mu \mathrm{mol} \mathrm{I}^{-1}\right)$ \\
\hline Experiment 1 & & \\
$\quad$ Control (vehicle) & $16.4 \pm 1.4$ & $78.7 \pm 3.9$ \\
GABA $\left(100 \mu \mathrm{mol} \mathrm{I}^{-1}\right)$ & $19.3 \pm 1.8$ & $71.3 \pm 5.6$ \\
& & \\
Experiment 2 & $50.5 \pm 3.2$ & $88.4 \pm 6.1$ \\
$\quad$ Control (vehicle) & $47.6 \pm 8.7$ & $96.8 \pm 17.3$ \\
Flumazenil $\left(1 \mu \mathrm{mol} \mathrm{I}^{-1}\right)$ & & \\
\hline
\end{tabular}

Abbreviation: GABA, $\gamma$-amino-butyric-acid.

Data are expressed as mean \pm s.e.m.

mechanisms. At low concentrations, midazolam-induced vasodilation is mostly endothelium dependent, whereas at high concentrations, it is mostly endothelium independent and characterized by a reduced calcium sensitivity of the aortic rings. The evidence is that at the lowest effective midazolam concentration, the vasodilation of rings without endothelium was less than the vasodilation of rings with 


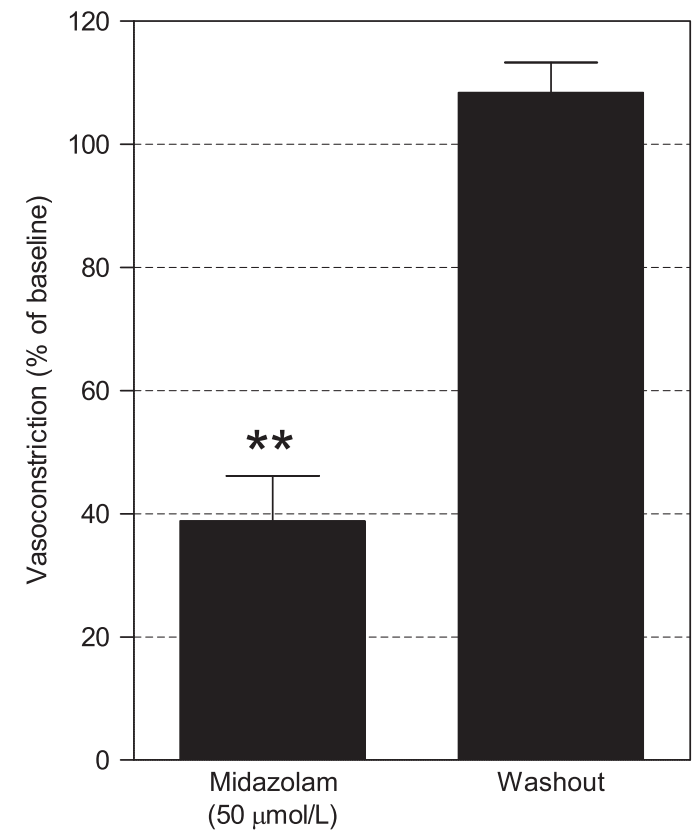

Figure 2 Reversal of midazolam's effect after midazolam washout. Mouse aortic rings were precontracted with $1 \mu \mathrm{molI}^{-1}$ phenylephrine. Values are means \pm s.e.m. for 12 samples of aortic rings obtained from three mice. ${ }^{*} P<0.05$ by paired Student's $t$-test.

endothelium. In contrast, at the highest midazolam concentration, the vasodilation was similar in rings both with and without endothelium. In addition, the dose-response curves showed that midazolam only reduced the vasoconstriction induced by increasing doses of calcium chloride at the high concentration.

Our findings also suggest that the different BDZ molecules have different endothelium-dependent mechanisms for stimulation of vasodilation. For example, the BDZ diazepam induces an endothelium-dependent vasodilation involving endothelial NO production in rodents. ${ }^{18,19}$ In contrast, our results excluded NO involvement in the mechanism of the BDZ midazolam because the NOS inhibitor NGnitro-L-arginine methyl ester did not modify midazolam-induced vasodilation (Figure 3b).

In agreement with our results, evidence that midazolam-induced endothelium-dependent vasodilation does not involve NO has been reported in experiments using isolated porcine coronary arteries. ${ }^{11}$ In those coronary arteries, NG-nitro-L-arginine methyl ester did not attenuate midazolam-induced vasodilation, but tetraethylamonium chloride did. Tetraethylamonium chloride is an inhibitor of the endothelial calcium-sensitive potassium channels, whose inhibition induces relaxation through the hyperpolarization of vascular smooth muscle membrane. ${ }^{26}$ In support of the hypothesis that midazolam induces hyperpolarization, suggested by Klockgether-Radke et al., ${ }^{11}$ we found that the vasodilation resulting from the low dose, or 'endothelial dose,' of midazolam in $\mathrm{KCl}$-precontracted rings was lower than the vasodilation observed in phenylephrine-precontracted rings (Figures 1a and b). Depolarization of the vascular smooth muscle cells of aortic rings induced by the high concentration of $\mathrm{KCl}$ in the bath $\left(80 \mathrm{mmoll}^{-1}\right)$ may overwhelm the hyperpolarization induced by the 'endothelial dose' of midazolam. In contrast, this effect did not occur in phenylephrine-precontracted rings where the $\mathrm{KCl}$ concentration was in the physiological range $\left(4.7 \mathrm{mmoll}^{-1}\right)$. Furthermore, evidence for a cell-hyperpolarizing effect of midazolam has been documented in in vitro studies of hippocampal neurons. In these studies, low con-
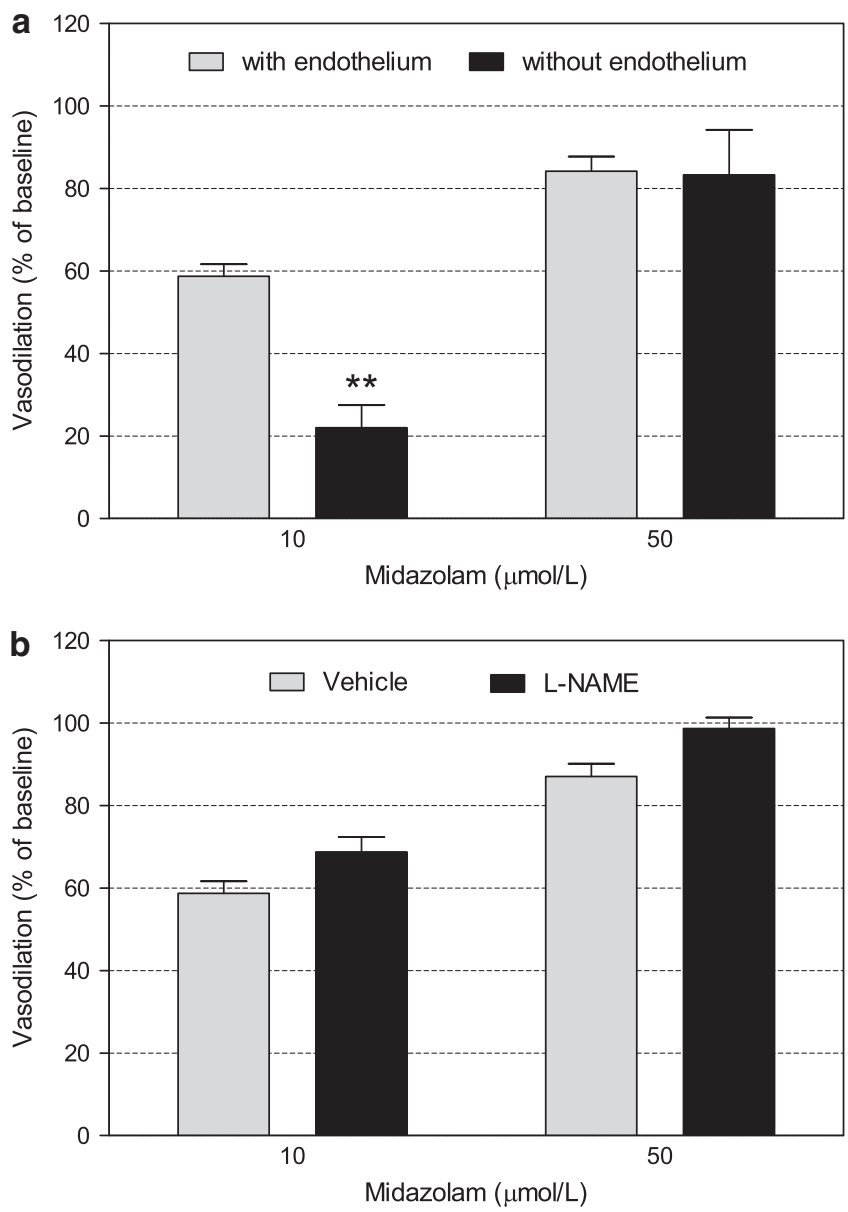

Figure 3 The dose-dependent vasodilatory effect of midazolam on $1 \mu \mathrm{mol} \mathrm{I-1}$ phenylephrine-precontracted mouse aortic rings. (a) Rings lacking endothelium were compared with endothelium intact rings. (b) Rings were incubated for $40 \mathrm{~min}$ with the nitric oxide synthase inhibitor NG-nitro-Larginine methyl ester (L-NAME; $300 \mu \mathrm{molI}^{-1}$ ) and were compared with vehicle. Values are means \pm s.e.m. for 12 samples of aortic rings obtained from three mice. ${ }^{* *} P<0.01$ by two-way analysis of variance and post-test pairwise comparisons by Bonferroni's method.

centrations of midazolam, which are not appropriate to stimulate $\mathrm{GABA}_{\mathrm{A}}$ receptors, can induce membrane hyperpolarization through an increase of calcium-sensitive potassium conductance. ${ }^{27}$ Taken together these data suggest two considerations. First, different BDZ molecules can have different endothelium-dependent mechanisms of vasodilation. Second, the reduction of calcium-sensitive potassium conductance induced by midazolam inhibition of calcium-sensitive potassium channels is the most likely mediator of midazolam-induced endothelium-dependent vasodilation.

Because $\mathrm{GABA}_{\mathrm{A}}$ receptors have been involved in BDZ-induced vasodilation in different vascular beds ${ }^{22,25}$ and because immunohistochemical studies showed the presence of a non-neuronal $\mathrm{GABA}_{\mathrm{A}}$ receptor in endothelial cells, ${ }^{28}$ we tested the potential role of the $\mathrm{GABA}_{\mathrm{A}}$ receptor in midazolam-induced vasodilation. Our results exclude both the hypothesis that $\mathrm{GABA}_{\mathrm{A}}$ receptor mediates midazolam-induced vasodilation and that $\mathrm{GABA}_{\mathrm{A}}$ receptor can be potentially involved in mouse aorta vasodilation. We found that the $\mathrm{GABA}_{\mathrm{A}}$ receptor inhibitor flumazenil did not reduce midazolam-induced vasodilation (Table 1) and that increasing doses of GABA did not modify the tone of the precontracted rings (data not shown). Thus, 


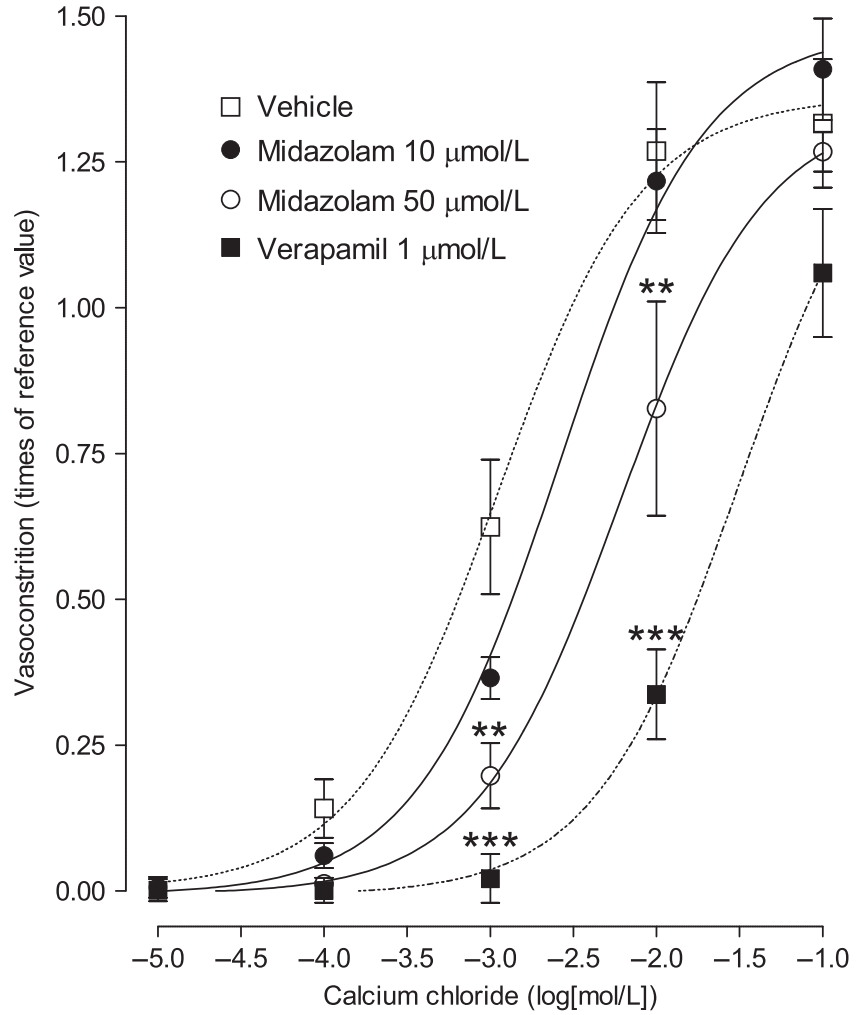

Figure 4 The dose-dependent vascular effect of midazolam on $\mathrm{CaCl}_{2-}$ induced vasoconstriction in mouse aortic rings. Vasoconstriction is expressed with reference to the maximal vasoconstriction reached by the same ring contracted with $60 \mathrm{mmoll}^{-1} \mathrm{KCl}$ under normal calcium conditions (reference value 1.0 in the $y$ axis). The calcium-channel-blocker verapamil $\left(1 \mu \mathrm{mol} \mathrm{I}^{-1}\right)$ was used as a positive control. Values are means \pm s.e.m. for 16 samples of aortic rings obtained from four mice. The dose-response curves are fitted with a three-parameter equation. ${ }^{* *} P<0.01,{ }^{* *} P<0.001$ vs. vehicle by two-way analysis of variance and post-test pairwise comparisons by Bonferroni's method.

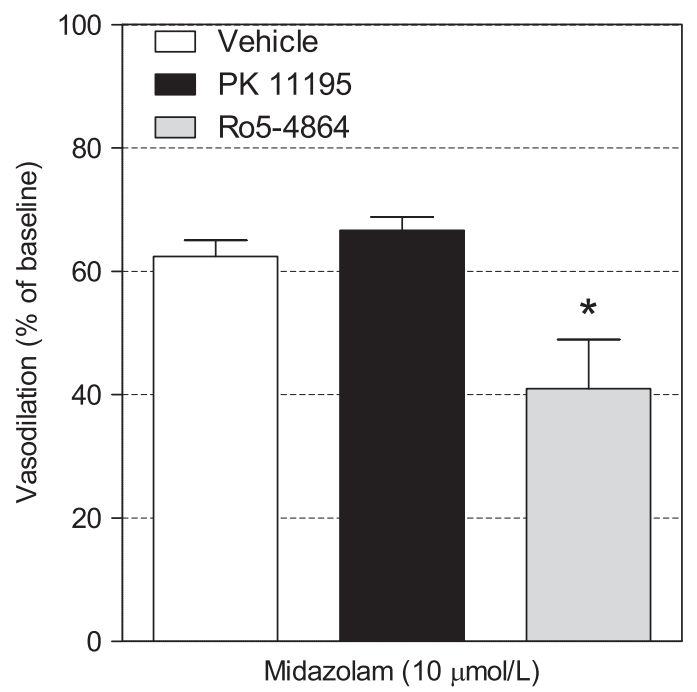

Figure 5 The vascular effect of midazolam on $1 \mu \mathrm{mol} \mathrm{I}^{-1}$ phenylephrineprecontracted rings incubated with the 'peripheral type benzodiazepine receptor' selective ligands PK $11195\left(1 \mu \mathrm{mol} \mathrm{I}^{-1}\right)$ and Ro5-4864 $\left(10 \mu \mathrm{moll}^{-1}\right)$. Values are means \pm s.e.m. for 12 samples of aortic rings obtained from three mice. ${ }^{*} P<0.05$ by one-way analysis of variance and post-test pairwise comparisons by Bonferroni's method. the $\mathrm{GABA}_{\mathrm{A}}$ receptor does not mediate midazolam-induced vasodilation and is not involved in mouse aorta vasodilation.

BDZs bind specifically to TSPOs in the vascular system and especially to TSPOs in vascular smooth muscle cells. ${ }^{29}$ Therefore, it has been suggested that TSPO can mediate BDZ-induced vasodilation. ${ }^{15}$ Several studies have shown that stimulation of TSPO with its specific ligands Ro5-4864 and PK 11195 can induce vasodilation through the inhibition of voltage-operated calcium channels. ${ }^{16,17}$ However, we found that TSPO does not mediate midazolam-induced vasodilation and that TSPO is not involved in mouse aorta vasodilation. Specifically, the incubation of precontracted rings with the TSPO ligand PK 11195 did not mitigate midazolam-induced vasodilation (Figure 5), and the stimulation of precontracted rings with increasing doses of Ro5-4864 did not induce vasodilation (data not shown). Previous evidence supports our results. First, in rat aorta, the enantiomers of quinoline propanamide $((-) \mathrm{PK} 14067$ and (+)PK14068), which have very different affinities for TSPO, are equally potent in reducing $\mathrm{CaCl}_{2}$-induced vasoconstriction. ${ }^{17}$ Second, the affinity of $\mathrm{BDZ}$ for TSPO is in the nanomolar range, but the vasodilation effect occurs only at micromolar levels. ${ }^{17}$ However, although interactions between midazolam and TSPO do not appear to contribute to vasodilation, midazolam appears to be able to interact with endothelial TSPO and affect functions other than vasodilation..$^{30,31}$

Paradoxically, we observed that micromolar concentrations of Ro54864 reduced midazolam-induced vasoconstriction (Figure 5), but increasing doses of Ro5-4864 did not modify vascular tone compared with vehicle. To explain these results, it has been suggested that Ro54864 also possesses a low affinity for the voltage-operated calcium channels and that at micromolar concentrations, it can probably compete for the same BDZ-binding site on voltage-operated calcium channels. ${ }^{32,33}$ These observations suggest that at high concentrations, midazolam possesses the calcium-channel antagonist property of acting directly on voltage-operated calcium channels. ${ }^{12,17,34-37}$

The calcium-antagonist property of midazolam supports the endothelium-independent mechanism of midazolam-induced vasodilation that we observed in this study. In fact, endothelium-deprived rings were not different from endothelium-intact rings with respect to the vasodilation induced by the high dose of midazolam, and only the high dose of midazolam reduced $\mathrm{CaCl}_{2}$-induced vasoconstriction (Figures $3 \mathrm{a}$ and 4). Accordingly, Yamaguchi and Shiraishi ${ }^{12,13}$ showed that in rabbit mesenteric arteries that lacked endothelium, midazolam at $>10 \mu \mathrm{moll}^{-1}$ inhibited norepinephrine-induced contraction by inhibition of calcium influx through voltage- and receptor-operated calcium channels. Furthermore, many studies using the patch clamp technique have documented that midazolam can inhibit inward calcium current in different animal species and tissues. ${ }^{13,34,36,37}$

In this study, we have investigated the vasodilatory effect of midazolam; however, vasodilation has also been reported with other BDZs. In pilot experiments in which aortic rings were exposed to increasing doses of diazepam, we found a vasodilatory response that was comparable to that of midazolam (data not shown). In addition, other authors reported vasodilation induced by different BDZs, such as diazepam in rat aorta, ${ }^{18,19}$ canine arteries, ${ }^{9}$ and human umbilical arteries and veins; ${ }^{4}$ tetrazepam in aorta and portal vein of rats; ${ }^{10}$ flurazepam in canine arteries $;{ }^{9}$ and clonazepam in human umbilical arteries. ${ }^{4}$ Moreover, BDZs seem to have a generalized muscle relaxant effect as demonstrated by diazepam- and clonazepam-induced relaxation of uterine rings from rats ${ }^{38}$ and by diazepam- and flurazepaminduced relaxation of isolated taenia coli and longitudinal muscle of guinea pigs. ${ }^{39}$ This muscle relaxant property of BDZs characteristically 
occurs at micromolar concentrations and involves the ability of BDZs to reduce intracellular calcium influx.

This study has explored the mechanisms of midazolam-induced vasodilation. On one hand, our results justify the occurrence of cardiovascular side effects of midazolam used as a sedative or anesthetic. ${ }^{6-8}$ On the other hand, they could indicate midazolam as a potential antihypertensive agent. The antihypertensive effects of midazolam are quite speculative because we did not conduct experiments with midazolam in in vivo models of hypertension, and midazolam-induced vasodilation occurs at concentrations that are too high for general clinical practice. Nonetheless, the vascular effects of midazolam could be useful in emergency/urgency situations, such as in hypertensive crises. Specifically, under intravenous infusion, midazolam can reach micromolar concentrations in plasma ${ }^{6}$ and exert its vasodilative and sedative properties, which could be beneficial in the treatment of hypertensive crises.

In conclusion, this study demonstrates that midazolam induces vasodilation of mouse aorta through two different mechanisms of action. The first mechanism is endothelium-dependent and occurs at low midazolam concentrations. The second is endothelium-independent, occurs at high midazolam concentrations and may depend on midazolam's calcium-antagonist property. Neither the $\mathrm{GABA}_{\mathrm{A}}$ receptor nor TSPO appear to be involved in the vasodilatory effect of midazolam. Although our study provides evidence for a functional interaction between midazolam and voltage-operated calcium channels and previous studies have supported the view of a direct interaction, ${ }^{34-37}$ it would be worthwhile to test this interaction in drug-protein binding studies. From this perspective, midazolam could be considered for clinical trials for the treatment of hypertensive crises.

\section{CONFLICT OF INTEREST}

The authors declare no conflict of interest.

\section{ACKNOWLEDGEMENTS}

We would like to thank Mimi Zeiger of the Cardiovascular Research Institute at the University of California San Francisco for her kind review of the manuscript. This study was supported by a research grant from the Pier Silverio Nassimbeni Foundation. GLC was the recipient of a research grant from the Italian Society of Hypertension.

1 Walsh MP. The Ayerst Award Lecture 1990. Calcium-dependent mechanisms of regulation of smooth muscle contraction. Biochem Cell Biol 1991; 69: 771-800.

2 Braunwald E. Mechanism of action of calcium-channel-blocking agents. N Engl J Med 1982; 307: 1618-1627.

3 Spieker LE, Flammer AJ, Lüscher TF. The vascular endothelium in hypertension. Handb Exp Pharmacol 2006: (176 Part 2): 249-283.

4 Elgoyhen AB, Lorenzo PS, Rothlin RP, Spacavento D, Adler-Graschinsky E. Relaxant effects of benzodiazepines on isolated human umbilical arteries and veins. Auton Autacoid Pharmacol 1993; 13: 373-379.

5 Daniell HB. Cardiovascular effects of diazepam and chlordiazepoxide. Eur J Pharmacol 1975; 32: 58-65.

6 Sunzel M, Paalzow L, Berggren L, Eriksson I. Respiratory and cardiovascular effects in relation to plasma levels of midazolam and diazepam. Br J Clin Pharmacol 1988; 25: 561-569.

7 Agelink MW, Majewski TB, Andrich J, Mueck-Weymann M. Short-term effects of intravenous benzodiazepines on autonomic neurocardiac regulation in humans: a comparison between midazolam, diazepam, and lorazepam. Crit Care Med 2002; 30: 997-1006.

8 Marty J, Gauzit R, Lefevre P, Couderc E, Farinotti R, Henzel C, Desmonts JM. Effects of diazepam and midazolam on baroreflex control of heart rate and on sympathetic activity in humans. Anesth Analg 1986; 65: 113-119.

9 Ishii K, Kano T, Ando J. Pharmacological effects of flurazepam and diazepam on isolated canine arteries. Jpn J Pharmacol 1983; 33: 65-71.

10 Pérez-Guerrero C, Suárez J, Herrera MD, Marhuenda E. Vasodilating effects of tetrazepam in isolated vascular smooth muscles: comparison with cromakalim and diltiazem. Pharmacol Res 1997; 36: 237-242.
11 Klockgether-Radke AP, Pawlowski P, Neumann P, Hellige G. Mechanisms involved in the relaxing effect of midazolam on coronary arteries. Eur J Anaesth 2005; 22: $135-139$.

12 Yamaguchi S, Kanmura Y, Yoshimura N. Effects of midazolam on contractions in smooth muscle of the rabbit mesenteric artery. Anesth Analg 1997; 84: 199-205.

13 Shiraishi Y, Ohashi M, Kanmura Y, Yamaguchi S, Yoshimura N, Itoh T. Possible mechanisms underlying the midazolam-induced relaxation of the noradrenaline-contraction in rabbit mesenteric resistance artery. Br J Pharmacol 1997; 121: 1155-1163.

14 Papadopoulos V, Baraldi M, Guilarte TR, Knudsen TB, Lacapere JJ, Lindemann P, Norenberg MD, Nutt D, Weizman A, Zhang MR, Gavish M. Translocator protein (18kDa): new nomenclature for the peripheral-type benzodiazepine receptor based on its structure and molecular function. Trends Pharmacol Sci 2006; 27: 402-409.

15 Veenman L, Gavish M. The peripheral-type benzodiazepine receptor and the cardiovascular system. Implications for drug development. Pharmacol Ther 2006; 110: 503-524.

16 Erne P, Chiesi M, Longoni S, Fulbright J, Hermsmeyer K. Relaxation of rat vascular muscle by peripheral benzodiazepine modulators. J Clin Invest 1989; 84: 493-498.

17 French JF, Rapoport RM, Matlib MA. Possible mechanism of benzodiazepine-induced relaxation of vascular smooth muscle. J Cardiovasc Pharmacol 1989; 14: 405-411.

18 Park S-E, Sohn J-T, Kim C, Chang KC, Shin I-W, Park K-E, Lee H-K, Chung Y-K. Diazepam attenuates phenylephrine-induced contractions in rat aorta. Anesth Analg 2006; 102: 682-689.

19 Galindo A, Vargas ML, García Estañ J, Fuentes T, Hernández J. Synergistic interaction of diazepam with $3^{\prime}, 5^{\prime}$-cyclic adenosine monophosphate-elevating agents on rat aortic rings. Eur J Pharmacol 2001; 428: 269-275.

20 Klockgether-Radke AP, Thudium A, Frerichs A, Kettler D, Hellige G. High-dose midazolam and the attenuation of the contractile response to vasoconstrictors in coronary artery segments. Eur J Anaesth 2003; 20: 289-293.

21 Vecchione C, Patrucco E, Marino G, Barberis L, Poulet R, Aretini A, Maffei A, Gentile MT, Storto M, Azzolino O, Brancaccio M, Colussi GL, Bettarini U, Altruda F, Silengo L, Tarone G, Wymann MP, Hirsch E, Lembo G. Protection from angiotensin II-mediated vasculotoxic and hypertensive response in mice lacking PI3Kgamma. J Exp Med 2005; 201: 1217-1228.

22 Anwar N, Mason DF. Two actions of gamma-aminobutyric acid on the responses of the isolated basilar artery from the rabbit. Br J Pharmacol 1982; 75: 177-181.

23 Hof RP, Vuorela HJ. Assessing calcium antagonism on vascular smooth muscle: a comparison of three methods. J Pharmacol Methods 1983; 9: 41-52.

24 Shirakawa J, Hosoda K, Taniyama K, Matsumoto S, Tanaka C. gamma-Aminobutyric acid-A receptor-mediated suppression of 5-hydroxytryptamine-induced guinea-pig basilar artery smooth muscle contractility. Blood Vessels 1989; 26: 129-136.

25 Monasterolo LA, Trumper L, Elías MM. Reversal of benzodiazepine-induced renal vasculature relaxation with flumazenil. Eur J Pharmacol 2002; 449: 155-158.

26 Griffith TM. Endothelium-dependent smooth muscle hyperpolarization: do gap junctions provide a unifying hypothesis? Br J Pharmacol 2004; 141: 881-903.

27 Carlen PL, Gurevich N, Polc P. Low-dose benzodiazepine neuronal inhibition: enhanced Ca2+-mediated K+-conductance. Brain Res 1983; 271: 358-364.

28 Imai H, Okuno T, Wu JY, Lee TJ. GABAergic innervation in cerebral blood vessels: an immunohistochemical demonstration of L-glutamic acid decarboxylase and GABA transaminase. J Cereb Blood Flow Metab 1991; 11: 129-134.

29 French JF, Matlib MA. Identification of a high-affinity peripheral-type benzodiazepine binding site in rat aortic smooth muscle membranes. J Pharmacol Exp Ther 1988; 247: 23-28.

30 Joo HK, Oh SC, Cho EJ, Park KS, Lee JY, Lee EJ, Lee SK, Kim HS, Park JB, Jeon BH. Midazolam inhibits tumor necrosis factor-alpha-induced endothelial activation: involvement of the peripheral benzodiazepine receptor. Anesthesiology 2009; 110: 106-112.

31 Shany E, Hochhauser E, Halpern P, Vidne B, Gavish M, Geller E, Hasharoni A, Barak Y, Yakirevich V. Ro 5-4864 has a negative inotropic effect on human atrial muscle strips that is not antagonized by PK 11195. Eur J Pharmacol 1994; 253: 231-236.

32 Bolger GT, Abraham S, Oz N, Weissman BA. Interactions between peripheral-type benzodiazepine receptor ligands and an activator of voltage-operated calcium channels. Can J Physiol Pharmacol 1990; 68: 40-45.

33 Campiani G, Fiorini I, De Filippis MP, Ciani SM, Garofalo A, Nacci V, Giorgi G, Sega A Botta M, Chiarini A, Budriesi R, Bruni G, Romeo MR, Manzoni C, Mennini T. Cardiovascular characterization of pyrrolo[2,1-d][1,5]benzothiazepine derivatives binding selectively to the peripheral-type benzodiazepine receptor (PBR): from dual PBR affinity and calcium antagonist activity to novel and selective calcium entry blockers. J Med Chem 1996; 39: 2922-2938.

34 Ishizawa Y, Furuya K, Yamagishi S, Dohi S. Non-GABAergic effects of midazolam, diazepam and flumazenil on voltage-dependent ion currents in NG108-15 cells. Neuroreport 1997; 8: 2635-2638.

35 Chang KS, Feng MG, Davis RF. Midazolam produces vasodilation by mixed endothelium-dependent and -independent mechanisms. Anesth Analg 1994; 78: 710-717.

36 Yamakage M, Matsuzaki T, Tsujiguchi N, Honma Y, Namiki A. Inhibitory effects of diazepam and midazolam on $\mathrm{Ca} 2+$ and $\mathrm{K}+$ channels in canine tracheal smooth muscle cells. Anesthesiology 1999; 90: 197-207.

37 Buljubasic N, Marijic J, Berczi V, Supan DF, Kampine JP, Bosnjak ZJ. Differential effects of etomidate, propofol, and midazolam on calcium and potassium channel currents in canine myocardial cells. Anesthesiology 1996; 85: 1092-1099.

38 Kazanietz MG, Elgoyhen AB. Relaxant effect of benzodiazepines on uterine rings isolated from estrogen-treated rats. Eur J Pharmacol 1990; 185: 231-234.

39 Ishii K, Kano T, Akutagawa M, Makino M, Tanaka T, Ando J. Effects of flurazepam and diazepam in isolated guinea-pig taenia coli and longitudinal muscle. Eur J Pharmacol 1982; 83: 329-333. 